\title{
Farmacocinética, Farmacogenómica y Variabilidad interindividual.
}

\section{Pharmacokinetics, Pharmacogenomics and Interindividual variability}

\author{
Ana Luisa Robles-Piedras ${ }^{a}$, Alejandro Chehue-Romero ${ }^{b}$, Elena Olvera Hernández ${ }^{c}$
}

\begin{abstract}
:
Pharmacokinetics can be defined as the "relationship between the administered dose and the plasma drug concentration", and implies the study of the absorption, distribution, metabolism and excretion processes. Pharmacokinetic modifications help to explain the different responses that occur between different subjects, giving interindividual variability, at the same time, the pharmacokinetic approach to define interindividual variability in response to drugs needs a genetic explanation to understand it. Pharmacogenetics studies the genetic causes of individual DNA variations in drug response, and pharmacogenomics evaluate a genome-wide analysis (DNA, RNA level) of the genetic determinants of drug efficacy and toxicity.
\end{abstract}

Keywords:

Pharmacokinetics, pharmacogenomics, variability

\section{Resumen:}

La farmacocinética se puede definir como la "relación entre la dosis administrada y la concentración plasmática de un fármaco", y esto implica el estudio de los diferentes procesos de absorción, distribución, metabolismo y excreción. Las modificaciones en la farmacocinética ayudan a explicar las diferentes respuestas que se presentan entre diferentes sujetos, dándose así la variabilidad interindividual, a su vez, la aproximación farmacocinética para definir la variabilidad interindividual en la respuesta a los fármacos necesita obligatoriamente de una explicación genética para entender dicho concepto. La farmacogenética estudia las causas genéticas de las variaciones individuales del ADN en la respuesta a los fármacos, y la farmacogenómica, analiza todo el genoma (nivel de ADN, ARN) de los determinantes genéticos de la eficacia y toxicidad de los fármacos.

\section{Palabras Clave:}

Farmacocinética, farmacogenómica, variabilidad

\section{Introducción}

La farmacocinética se puede definir como la "relación entre la dosis administrada y la concentración plasmática de un fármaco, y esto implica el estudio de los diferentes procesos de absorción, distribución, metabolismo y excreción (ADME); en otras palabras, se encarga de estudiar "qué hace el organismo con el fármaco".

Cuando el fármaco se absorbe, puede pasar a la circulación sistémica sin modificaciones o sufrir un metabolismo de primer paso.

Los procesos relacionados con la absorción y el metabolismo de primer paso podrían afectar la

\footnotetext{
Autor de Correspondencia, Universidad Autónoma del Estado de Hidalgo, https://orcid.org/0000-0002-8697-605X, Email: roblesa@uaeh.edu.mx

b Universidad Autónoma del Estado de Hidalgo, https://orcid.org/0000-0003-3054-7544, Email: chehuea@uaeh.edu.mx

c Universidad Autónoma del Estado de Hidalgo, https://orcid.org/0000-0002-9704-4872, Email: olverae@uaeh.edu.mx
} 
concentración máxima $\left(\mathrm{C}_{\text {máx }}\right)$ que puede alcanzar el fármaco (Figura 1). La segunda parte de la curva está dominada por el proceso de eliminación o excreción, en esta fase el metabolismo del fármaco y su excreción son los procesos más importantes.

Las modificaciones en la farmacocinética ayudan a explicar las diferentes respuestas que se presentan entre diferentes sujetos, dándose así la variabilidad interindividual, y donde se pueden encontrar diferentes situaciones tales como la edad, el género, enfermedades, etc. Asimismo, los parámetros farmacocinéticos derivados del proceso ADME, varían de acuerdo a la vía de administración del fármaco, y entre los sujetos.

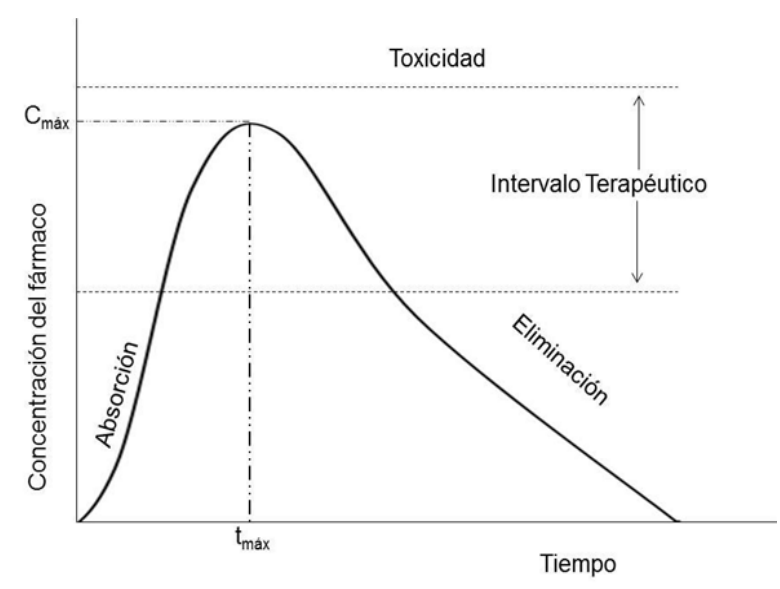

Figura 1. Curva que describe la concentración de un fármaco con respecto al tiempo, para una vía de administración oral.

Si bien algunos fármacos ejercen su efecto sin entrar a la circulación, la mayoría de ellos deben ingresar al organismo por vía enteral o parenteral para ser transportados por la sangre, donde atravesarán las membranas celulares y finalmente alcanzarán el objetivo molecular. La aproximación científica más adecuada hasta hace pocos años al problema de la variabilidad de la respuesta farmacológica en los pacientes, lo daba la farmacocinética. Sin embargo, los avances recientes en la medicina personalizada han demostrado que las variaciones genéticas en los genes que codifican las enzimas metabolizadoras de fármacos y los transportadores de membrana de fármacos pueden tener un impacto importante en su disposición y eficacia (Figura 2). Estas variaciones son parte integral de la explicación de las diferencias en la disposición de los fármacos entre y dentro de las poblaciones $\mathrm{y} / \mathrm{o}$ en los individuos (variabilidad interindividual). 1
El metabolismo de los fármacos consiste en reacciones químicas que involucran la oxidación de las moléculas (Fase I), principalmente mediadas por enzimas del citocromo P450, y reacciones de conjugación, tales como la glucuronidación, sulfatación y acetilación (Fase II). Hace ya más de 40 años que fue descubierto el primer polimorfismo en las reacciones de metabolización de los fármacos en cuanto a la acetilación. Ahora se sabe que la $\mathrm{N}$-acetiltransferasa (NAT) está controlada por dos genes (NAT1 y NAT2) de los cuales, NAT2 A y B son responsables de polimorfismos metabólicos clínicamente significativos. 2

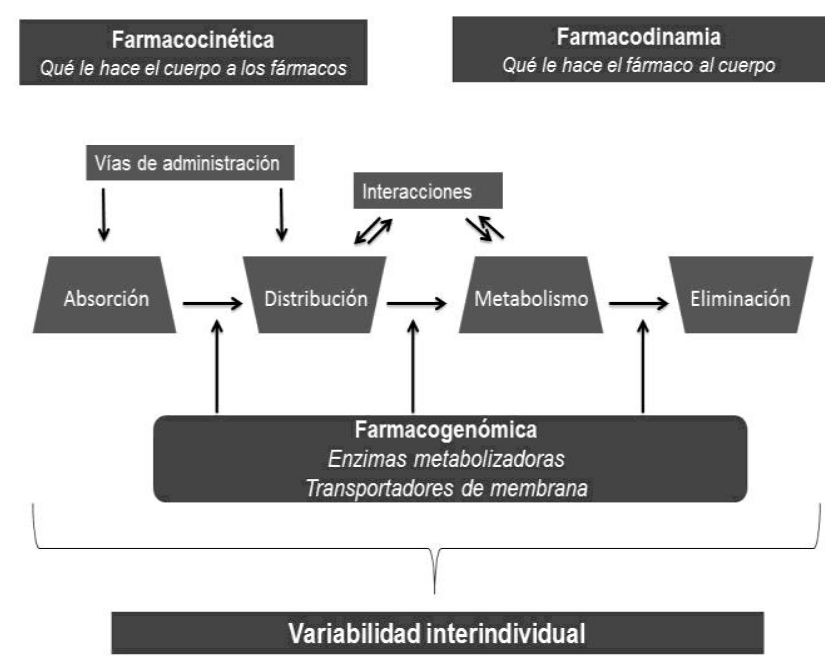

Figura 2. Curva que describe la concentración de un fármaco con respecto al tiempo, para una vía de administración oral.

De este modo, concentraciones variables de un fármaco pueden producir una variedad de resultados clínicos. Los acetiladores lentos tienen más efectos secundarios (por ejemplo: dapsona y procainamida) y los acetiladores rápidos tienen respuestas clínicas menos confiables (por ejemplo: isoniazida); asimismo, los acetiladores rápidos también tienen el potencial de producir más efectos secundarios en situaciones en las que un metabolito activo pueda ser responsable de toxicidad.

En este sentido, la aproximación farmacocinética para definir la variabilidad interindividual en la respuesta a los fármacos necesita obligatoriamente de una explicación genética para entender dicho concepto. Así, salen a la luz dos disciplinas La farmacogenética y la farmacogenómica, que son herramientas que permiten explicar y predecir la variabilidad en el proceso de ADME y la asociación con el éxito clínico o fracaso terapéutico por falta de efectividad - seguridad. Ambas disciplinas son herramientas importantes para la medicina personalizada. 3 
La farmacogenética generalmente se refiere al impacto que tiene la variación en un solo gen en la respuesta a un fármaco. Es la disciplina científica orientada al estudio de los aspectos genéticos relacionados con la variabilidad de la respuesta a los fármacos en individuos o poblaciones. La variación farmacogenética dentro de las poblaciones humanas puede afectar la farmacocinética al alterar el perfil ADME esperado de un fármaco. Por otro lado, la Farmacogenómica se ocupa del análisis de todo el genoma (nivel de ADN, ARN) de los determinantes genéticos de la eficacia y toxicidad de los fármacos. 4

De manera general, tanto la farmacocinética como la farmacodinamia, y la farmacogenética y farmacogenómica, están estrechamente relacionadas con la manera en la que un fármaco interactúa en el organismo, y es a través de estas interacciones, que se alcanza la eficacia o la toxicidad de los fármacos.

Conociendo cómo un determinado polimorfismo genético afecta al metabolismo y a la acción de los fármacos, es posible predecir para cada paciente qué medicamento es el que ofrece un mayor beneficio terapéutico y qué probabilidad existe de desarrollar una reacción adversa en función de su expresión genética. Sin embargo, Aunque el uso de la farmacogenómica ha avanzado durante las últimas dos décadas como herramienta para la individualización de dosis, no se debe descuidar la monitorización terapéutica de fármacos (TDM) para la individualización de dosis que, en última instancia, puede contribuir a la medicina de precisión. 5

\section{Conclusión}

EI TDM puede lograr concentraciones de fármaco objetivo en pacientes individuales con más precisión que lo que puede hacer la genotipificación de enzimas 0 transportadores que metabolizan fármacos. Sin embargo, los dos enfoques más que excluyentes, son complementarios entre sí, pues con la farmacogenética, la determinación del genotipo de las enzimas o transportadores que metabolizan el fármaco puede ser útil para seleccionar el fármaco y la dosis inicial, mientras que el TDM (aplicando la farmacocinética clínica), será útil para ajustar las dosis posteriores de acuerdo con las concentraciones del fármaco en pacientes individuales.

\section{Referencias}

[1] Lesko LJ, Schmidt S. Individualization of drug therapy: history, present state, and opportunities for the future. Clin Pharmacol Ther. 2012; 92(4): 458-66.

[2] Summerscales JE, Josephy PD. Human acetyl CoA:arylamine Nacetyltransferase variants generated by random mutagenesis. Mol Pharmacol. 2004; 65(1): 220-6.
[3] Ma Q, Lu AY. Pharmacogenetics, pharmacogenomics, and individualized medicine. Pharmacol Rev. 2011; 63(2): 437-59.

[4] Roses AD. Pharmacogenetics and the practice of medicine. Nature. 2000; 405(6788): 857-65.

[5] Jang SH, Yan Z, Lazor JA. Therapeutic drug monitoring: A patient management tool for precision medicine. Clin Pharmacol Ther. 2016; 99(2): $148-50$. 